\title{
Kynurenine promotes the goblet cell differentiation of HT-29 colon carcinoma cells by modulating Wnt, Notch and AhR signals
}

\author{
JOO-HUNG PARK, JEONG-MIN LEE, EUN-JIN LEE, DA-JEONG KIM and WON-BHIN HWANG \\ Department of Biology, Changwon National University, Changwon, Kyungnam 51140, Republic of Korea
}

Received August 31, 2017; Accepted February 7, 2018

DOI: $10.3892 /$ or.2018.6266

\begin{abstract}
Various amino acids regulate cell growth and differentiation. In the present study, we examined the ability of HT-29 cells to differentiate into goblet cells in RPMI and DMEM which are largely different in the amounts of numerous amino acids. Most of the HT-29 cells differentiated into goblet cells downregulating the stem cell marker Lgr5 when cultured in DMEM, but remained undifferentiated in RPMI. The goblet cell differentiation in DMEM was inhibited by 1-methyl-tryptophan (1-MT), an inhibitor of indoleamine 2,3 dioxygenase- 1 which is the initial enzyme in tryptophan metabolism along the kynurenine $(\mathrm{KN})$ pathway, whereas tryptophan and $\mathrm{KN}$ induced goblet cell differentiation in RPMI. The levels of Notch1 and its activation product Notch intracytoplasmic domain in HT-29 cells were lower in DMEM than those in RPMI and were increased by 1-MT in both media. HT-29 cells grown in both media expressed $\beta$-catenin at the same level on day 2 when goblet cell differentiation was not observed. $\beta$-catenin expression, which was increased by $1-\mathrm{MT}$ in both media, was decreased by KN. DMEM reduced Hes1 expression while enhancing Hath1 expression. Finally, aryl hydrocarbon receptor (AhR) activation moderately induced goblet cell differentiation. Our results suggest that KN promotes goblet cell differentiation by regulating Wnt, Notch, and AhR signals and expression of Hes1 and Hath1.
\end{abstract}

\section{Introduction}

Cell lines are usually maintained in defined media that commonly contain amino acids, vitamins, glucose and

Correspondence to: Dr Joo-Hung Park, Department of Biology, Changwon National University, 9 Sarim-Dong, Changwon, Kyungnam 51140, Republic of Korea

E-mail: parkjh@changwon.ac.kr

Abbreviations: AhR, aryl hydrocarbon receptor; KN, kynurenine; 1-MT, 1-methyl-L-tryptophan; IDO-1, indoleamine 2,3 dioxygenase-1; NICD, Notch intracytoplasmic domain; I3S, indoxyl 3-sulfate; I3C, indole-3-carbinol; DIM, 3,3'-diindolylmethane (DIM); FICZ, 6-formylindolo[3,2-b]carbazole.

Key words: DMEM, tryptophan, kynurenine, $\beta$-catenin, Notch1, goblet cell inorganic salts for normal cell metabolism. However, the composition of medium formulations vary widely in concentrations of glucose and other metabolic precursors, including amino acids. Thus, many types of cells showed different responses to culture media in regards to proliferation and differentiation. Th17 differentiation was induced more efficiently in Iscove's modified Dulbecco's medium (IMDM) than in RPMI (1). Bone marrow-derived dendritic cells in IMDM expressed higher levels of co-stimulatory and MHC II molecules, compared to the cells generated in RPMI (2). In addition, hepatocyte differentiation and propagation and phenotype of corneal stroma-derived stem cells were modulated by culture media $(3,4)$. Subsequently, the underlying mechanisms of the medium-induced changes in cell proliferation and differentiation have been partially elucidated. Differentiation of Th17 cells was increased by endogenous aryl hydrocarbon receptor (AhR) agonists derived from aromatic amino acids such as tryptophan, which is underrepresented in RPMI compared with IMDM (1). Mesenchymal stem cells co-cultured with AML12 liver cells were able to differentiate into hepatocytelike cells expressing hepatocyte-specific markers including albumin, $\alpha$-fetoprotein and cytokeratin 18 mRNAs, which were expressed at the initial 7-day culture in DMEM while being expressed during the 7- to 14-day culture in DMEM/ F12 (3). In a study using MDA-MB-231 breast cancer cells, $25.6 \%$ of genes were expressed at significantly different levels in cells grown in MEM, DMEM or RPMI (5). HT-29 cells, which remain undifferentiated in medium containing glucose, became differentiated into enterocytes upon removal of glucose $(6,7)$.

HT-29 cells, a human colon carcinoma cell line, can express, upon exposure to the appropriate inducers (including sodium butyrate, lack of glucose in culture medium, 12-O-tetradecanoylphorbol-13-acetate and forskolin) distinct intestinal lineage-specific markers, differentiating along different lineages that resemble those found in the normal intestinal epithelium $(6,8)$. Therefore, they are considered multipotent, similar to the stem cells of the intestinal crypt (9) and have been extensively used as an in vitro model for the study of the differentiation and proliferation of intestinal stem cells.

Various amino acids regulate cell growth and differentiation either by activating signaling pathways or by their metabolites. Leucine, arginine and glutamine activate the mammalian target of rapamycin (mTOR) signaling that controls cell growth and mRNA translation (10-12). Glutamine 
is a precursor of UDP-N-acetylglucosamine, a substrate for cellular glycosyltransferases, to control $\mathrm{T}$ cell self-renewal and malignancy (13). Metabolisms of threonine and leucine and isoleucine are required for stem cell self-renewal and adipocyte differentiation, respectively $(14,15)$. In addition, tryptophan metabolites such as kynurenine (KN) and kynurenic acid (KA) are ligands for AhR, a ligand-dependent transcription factor to regulate cell growth and differentiation $(16,17)$, and other aromatic amino acids, including histidine, tyrosine and phenylalanine, could generate precursors for AhR ligands (18).

DMEM contains higher amounts of aromatic as well as branched chain amino acids than RPMI. Thus, studies concerning the growth and differentiation of certain cancer stem cells in different media containing different amounts of amino acids such as DMEM and RPMI could elucidate the roles of amino acids in cell growth and differentiation.

In the present study, we compared the differentiating ability of HT-29 cells in RPMI-1640 (subsequently referred to as RPMI) and DMEM which largely differ in regards to the amounts of many amino acids, including tryptophan (concentrations of L-histidine, L-tyrosine, L-phenylalanine, and L-tryptophan, which are 15, 29, 15 and $5 \mathrm{mg} / \mathrm{l}$, respectively, in RPMI 1640, rise to 42, 104, 66 and $16 \mathrm{mg} / \mathrm{l}$, respectively, in DMEM). We also investigated which amino acids and metabolites contribute to this and how they function. When we cultured HT-29 cells in RPMI and DMEM, it was observed that most of the HT-29 cells differentiated into goblet cells downregulating the stem cell marker Lgr5 when cultured in DMEM, but remained undifferentiated in RPMI. We demonstrated that KN, an indoleamine 2,3 dioxygenase-1 (IDO-1)-mediated tryptophan metabolite, promoted goblet cell differentiation and reduced $\beta$-catenin expression. In addition, the levels of Notch1 and its active product Notch intracytoplasmic domain (NICD) were decreased in DMEM when compared to the levels in RPMI. DMEM reduced expression of transcriptional repressor Hes1 while upregulated expression of Hath1, a transcriptional activator mediating differentiation of secretory lineages. Finally, AhR activation moderately induced goblet cell differentiation.

\section{Materials and methods}

Cell culture. HT-29 human epithelial cell line was purchased from the American Type Culture Collection (ATCC; Rockville, MD, USA). Cells were maintained in RPMI-1640 and DMEM (Gibco; Life Technologies, Carlsbad, CA, USA) supplemented with $10 \%(\mathrm{v} / \mathrm{v})$ heat-inactivated fetal bovine serum (FBS; Sigma-Aldrich, St. Louis, MO, USA), 100 U/ml penicillin, $100 \mu \mathrm{g} / \mathrm{ml}$ streptomycin and $0.25 \mu \mathrm{g} / \mathrm{ml}$ fungizone (Life Technologies) in a $5 \%$ humidified incubator at $37^{\circ} \mathrm{C}$. The cell number and viability were assessed by exclusion of trypan blue dye using a hemacytometer. For experiments, cells were seeded in a 24 -well plate at a density of $1 \times 10^{5}$ cells/well. Cells were observed under an inverted microscope for morphologic assessment.

Chemicals and reagents. Indoxyl 3-sulfate (I3S), indole-3-carbinol (I3C), 3,3'-diindolylmethane (DIM), 1-methyl-L-tryptophan and L-kynurenine were purchased from Sigma-Aldrich. 6-Formylindolo[3,2-b]carbazole (FICZ)
Table I. Primers used in the RT-PCR.

\begin{tabular}{|c|c|c|c|c|}
\hline Name & $\begin{array}{l}\text { Nucleotide } \\
\text { sequence }\end{array}$ & $\begin{array}{l}\text { Annealing } \\
\text { temp. }\left({ }^{\circ} \mathrm{C}\right)\end{array}$ & Cycles $^{\mathrm{a}}$ & $\begin{array}{l}\text { Size }^{b} \\
\text { (bp) }\end{array}$ \\
\hline huhgprtfw & 5'-ggccatcacattgtagecct-3' & 58 & 30 & 408 \\
\hline huhgprtrv & 5'-gtcaagggcatatcctacaac-3' & & & \\
\hline humuc $2 \mathrm{fw}$ & 5'-agcacttcgagttcgactgc-3' & 58 & 30 & 600 \\
\hline humuc2rv & 5'-ggatcttcacgcagctgaag-3' & & & \\
\hline hualpifw & $5^{\prime}$-atgtgtggaaccgcactgag-3' & 58 & 35 & 411 \\
\hline hualpirv & $5^{\prime}-\mathrm{ctttg} \operatorname{ctg} t c c t g a g c c t t g-3^{\prime}$ & & & \\
\hline hulyzfw & 5'ggtgtgagttggccagaact-3' & 58 & 30 & 300 \\
\hline hulyzrv & 5'-cttgtggatcacggacaacc-3' & & & \\
\hline huahrfw & 5'-ttggctagcetgctgccttt-3' & 58 & 30 & 350 \\
\hline huahrrv & $5^{\prime}$-gacgctgaaattcagctcgg-3' & & & \\
\hline hucyp1a1fw & 5'-aggcctgaagaatccaccag-3' & 58 & 35 & 760 \\
\hline hucyp1a1rv & 5'-gtgctcaatcaggctgtctg-3' & & & \\
\hline hulgr5fw & 5'-aaacctctccagctgggtag-3' & 58 & 35 & 590 \\
\hline hulgr5rv & 5'-ttcagcgatcggaggctaag-3' & & & \\
\hline huhes1fw & $5^{\prime}$-agccagtgtcaacacgacac-3' & 58 & 35 & 637 \\
\hline huhes1rv & 5'-aagcaaactggccatcggga-3' & & & \\
\hline huhath1fw & 5'-cactttgcagggcatctgca-3' & 58 & 35 & 410 \\
\hline huhath1rv & 5'-gccatctgcagggtctcata-3' & & & \\
\hline
\end{tabular}

${ }^{a}$ Indicates the number of cycles of amplification. ${ }^{b}$ Indicates the expected size of PCR products.

was obtained from Enzo Life Sciences (Farmingdale, NY, USA). AhR ligands were dissolved in dimethyl sulfoxide (DMSO) and 0.1\% DMSO v/v was used as vector control. Antiactivated Notch1 Ab was from Abcam (Cambridge, MA, USA) and anti-non-phospho (active) $\beta$-catenin (Ser33/37/Thr41) Ab and anti- $\beta$-actin Ab were from Cell Signaling Technologies (Danvers, MA, USA). Jagged-1 peptide was obtained from AnaSpec (Fremont, CA, USA).

RNA preparation, $R T-P C R$ and real-time PCR. Total cellular RNA was extracted from cells using the RNAzol method (Tel-Test, Inc., Friendswood, TX, USA). For PCR analysis, RNA was used after the contaminating DNA was completely removed by DNase I treatment. RT-PCR analysis was performed using pairs of oligonucleotide primers. The PCR products were confirmed to correspond to their original sequence by DNA sequencing. Gene-specific primers, number of cycles of amplification, annealing temperature, and expected size of the PCR product are listed in Table I. Real-time PCR was performed to quantitate PCR products. Power SYBR-Green PCR Master Mix and Real-Time PCR System (7300; Applied Biosystems, Foster City, CA, USA) were used.

Western blotting. Cells or tissues were homogenized in lysis buffer containing $20 \mathrm{mM}$ Tris- $\mathrm{HCl}$ (pH 7.4), $1 \mathrm{mM}$ EDTA (pH 8.0), $50 \mu \mathrm{M}$ sodium vanadate, $20 \mathrm{mM}$ $p$-nitrophenylphosphate, $50 \mathrm{mM}$ sodium fluoride, leupeptin $(0.5 \mu \mathrm{g} / \mathrm{ml})$, aprotinin $(10 \mu \mathrm{g} / \mathrm{ml})$ and soybean trypsin inhibitor $(10 \mu \mathrm{g} / \mathrm{ml})$. Proteins size-fractionated using sodium dodecyl 


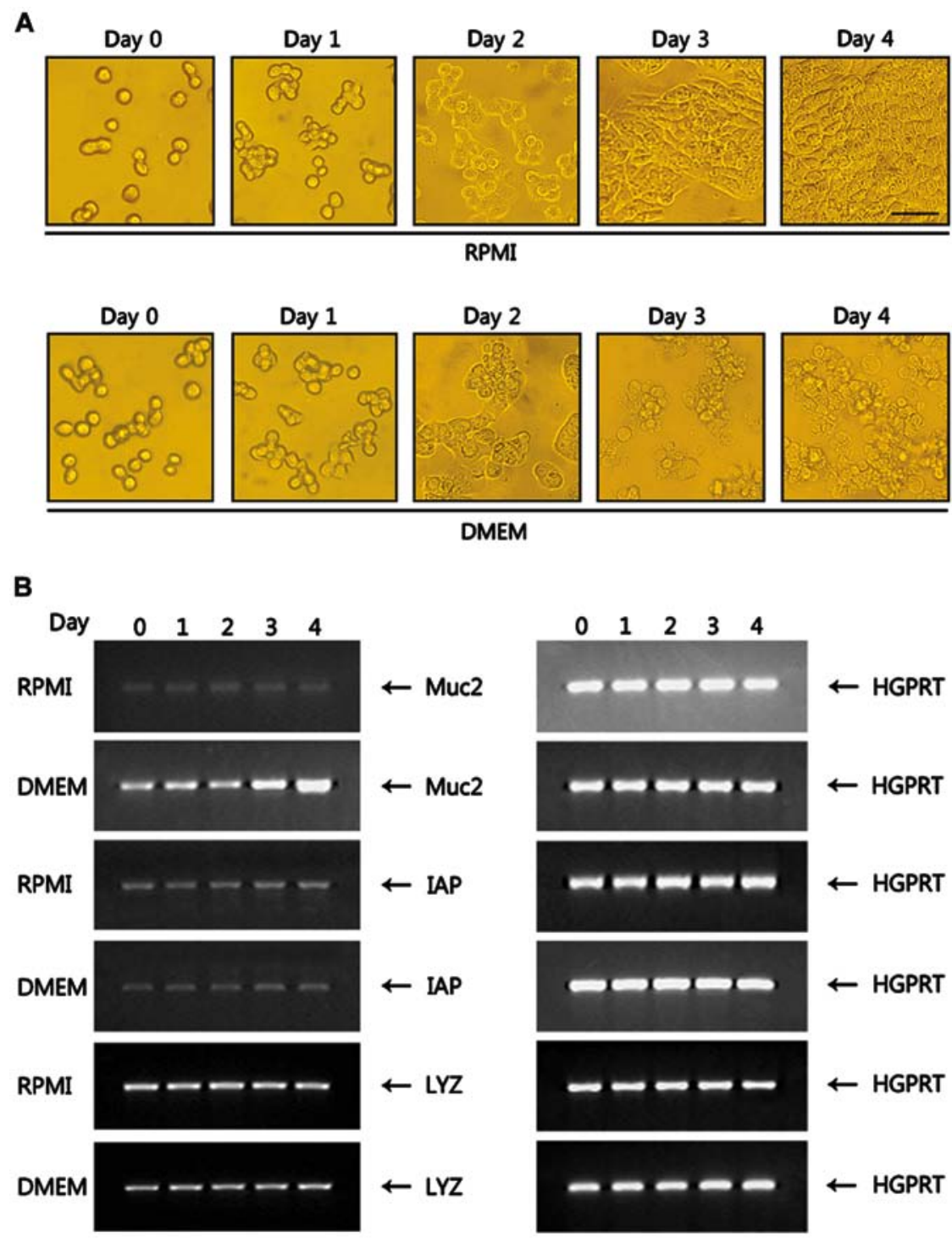

Figure 1. DMEM induces goblet cell differentiation from HT-29 colon cancer stem cells. (A) HT-29 cells seeded into a $24-w e l l$ plate at a density of $1 \times 10^{5}$ cells/ well were grown up to 4 days in RPMI or DMEM and observed under an inverted microscope. Scale bar, $50 \mu \mathrm{m}$. (B) For lineage-specific characterization, cells grown in RPMI or DMEM were harvested for RNA analysis by RT-PCR using lineage-specific primers (Table I). Results are representative of 3 separate experiments which showed similar results.

sulfate-polyacrylamide gel electrophoresis (SDS-PAGE) were transferred to polyvinylidene difluoride (PVDF) membranes, and the blots were blocked with $3 \%$ bovine serum albumin in TBS buffer (20 mM Tris- $\mathrm{HCl} \mathrm{pH} \mathrm{7.5/137} \mathrm{mM} \mathrm{NaCl).} \mathrm{The}$ blots were sequentially treated with primary and secondary antibodies in Tris-buffered saline with Tween-20 (TBST) (20 mM Tris- $\mathrm{HCl} \mathrm{pH} 7.5 / 137 \mathrm{mM} \mathrm{NaCl} / 0.1 \%$ Tween-20) with intermittent washing with TBST. Immunodetection detection was performed with the EzWestLumi Plus kit (ATTO Corp, Tokyo, Japan). Densitometric analysis was performed using Image Master 2-D Platinum software (Amersham Biosciences, Pisactaway, NJ, USA) according to the protocols provided by the manufacturer.

Statistical analysis. All experiments were performed three times, and a representative experiment is shown. Data are presented as the mean \pm SD and analyzed by the paired Student's t-test. A value of $\mathrm{P}<0.05$ was considered statistically significant.

\section{Results}

Differentiation of goblet cells from HT-29 cells is induced in DMEM. HT-29 cells, which are routinely maintained in RPMI or MEM, grow as monolayers $(18,19)$. HT-29 cells seeded in a $24-w e l l$ plate at a density of $1 \times 10^{5}$ cells/well in RPMI were grown up to 4 days until achieving $>90 \%$ confluency in culture dishes. HT-29 cells in RPMI did not show any morphological changes during the culture period and remained as monolayers (Fig. 1A). When HT-29 cells were cultured in DMEM, the cells began to show morphological changes on day 3 , including fine blebbings of secretion material at the cell surface, which is characteristic of goblet cells. At day 4, most of the HT-29 cells appeared to differentiate into goblet cells (Fig. 1A). To verify goblet cell differentiation, RNA prepared from HT-29 cells grown in RPMI and DMEM was analyzed for Muc2, a molecular marker of goblet cells. Muc2 expression, which was of a background level in HT-29 cells grown in RPMI, was greatly increased in HT-29 cells cultured 
A

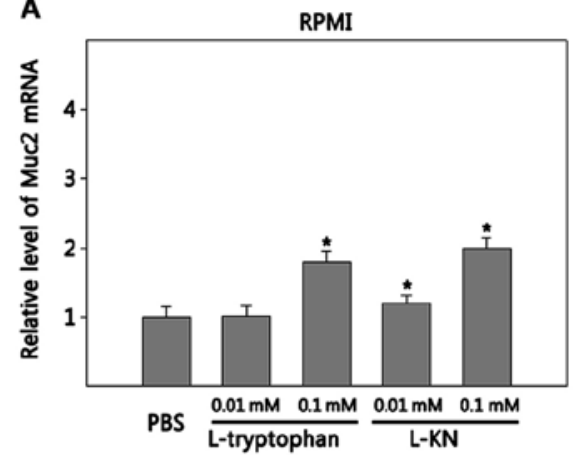

B

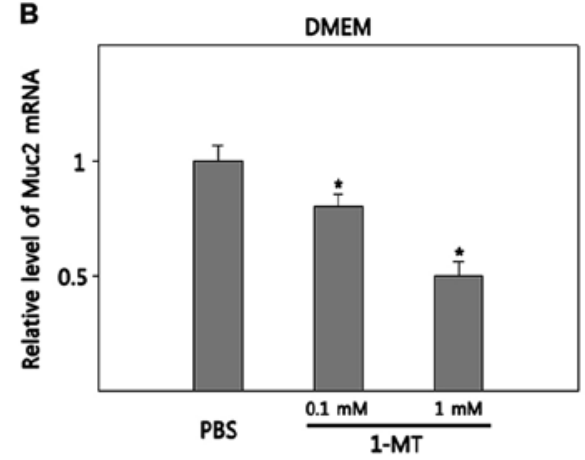

C

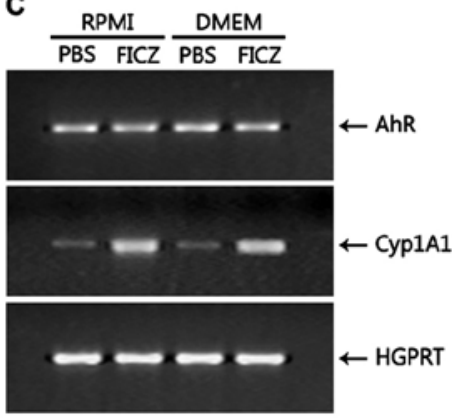

D

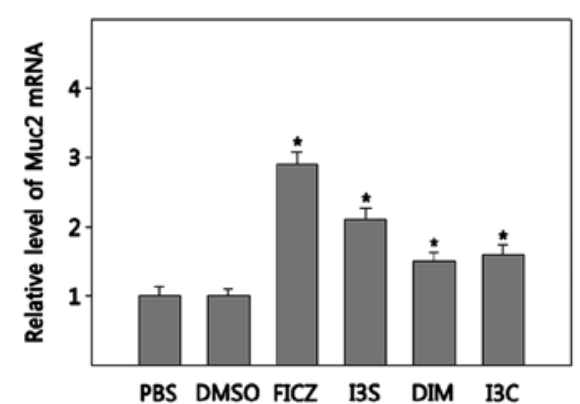

$\mathbf{E}$

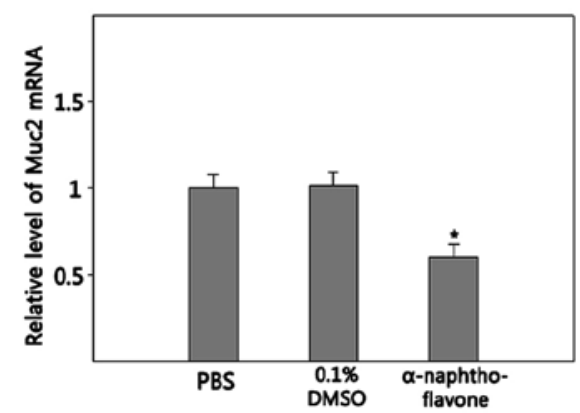

Figure 2. Muc2 expression is modulated by tryptophan metabolism and is enhanced by AhR activation. HT-29 cells seeded in a 24-well plate at a density of $1 \times 10^{5}$ cells/well were grown up to 4 days in RPMI and DMEM supplemented with varying amounts of (A) tryptophan (0.01-0.1 mM) or KN (0.1-1 mM) and (B) 1-MT (0.1-1 mM), respectively, and harvested for RNA analysis by real-time PCR. (C) HT-29 cells in RPMI or DMEM were cultured for $48 \mathrm{~h}$ in the absence or presence of FICZ $(1 \mu \mathrm{M})$ and harvested for RNA analysis by RT-PCR. HT-29 cells seeded into a 24 -well plate at a density of $1 \times 10^{5}$ cells/well were grown up to 4 days in (D) RPMI in the presence of FICZ $(1 \mu \mathrm{M})$, I3S (10 $\mu \mathrm{M})$, DIM $(10 \mu \mathrm{M})$ or I3C $(10 \mu \mathrm{M})$, or in (E) DMEM in the presence of $\alpha$-naphthoflavone $(1 \mu \mathrm{M})$ or $0.1 \%$ DMSO, and harvested for RNA analysis by real-time PCR. Relative levels of HGPRT-normalized Muc2 mRNA expression are shown. Results are representative of 3 separate experiments which showed similar results. " $\mathrm{P}<0.05$ compared with the PBS control.

in DMEM, 5.0-fold at day 4 compared with RPMI (Fig. 1B). Intestinal alkaline phosphatase (IAP), a marker of enterocytes, was weakly expressed in both RPMI and DMEM without any change during the culture period. HT-29 cells are able to differentiate into Paneth cells (20). The Paneth cell differentiation marker lysozyme was expressed at a basal level both in RPMI and DMEM with no changes in expression during the culture period (Fig. 1B), suggesting that the DMEM-induced differentiation of goblet cells from HT-29 cells is lineage-specific. When we did similar experiments with Caco- 2 cells, a human colon carcinoma cell line, we observed fine blebbings of secretion material at the cell surface when cells were grown in DMEM, but not in RPMI (data not shown).

Tryptophan and its metabolite KN promote the differentiation of goblet cells from HT-29 cells. Tryptophan, which is richer in DMEM compared with RPMI, is metabolized along 4 pathways converting to many physiologically important metabolites: i) hydroxylation making serotonin and melatonin; ii) decaroboxylation producing tryptamine; iii) transamination producing indolepyruvic acid; and (4) the KN pathway making KN and its metabolites (21). Thus, we examined whether tryptophan and its metabolites promote goblet cell differentiation. HT-29 cells were grown in RPMI supplemented with L-tryptophan to adjust levels to those in DMEM. To measure the effects of tryptophan on goblet cell differentiation, we quantified Muc2 RNA expression. Tryptophan significantly increased Muc2 expression compared with RPMI ( 1.8-fold increase at $0.1 \mathrm{mM}$ tryptophan, $\mathrm{P}=0.0006)$ (Fig. 2A), although its effect was not as dramatic as DMEM ( $\sim 5$-fold increase in DMEM compared with RPMI, Fig. 1B) in promoting Muc2 expression, suggesting that other factors in DMEM contribute to goblet cell differentiation. Among the 4 tryptophan degradation pathways, the KN pathway accounts for $\sim 95 \%$ of overall tryptophan degradation (21). IDO-1, which is the first enzyme to metabolize tryptophan along the KN pathway, is expressed in HT-29 cells (22). Thus, we examined whether KN stimulates goblet cell differentiation. HT-29 cells cultured in RPMI supplemented with L-KN showed enhanced expression of Muc2 dose-dependently; $1.2-(\mathrm{P}=0.016)$ and 2.0-fold $(\mathrm{P}=0.0005)$ at 0.1 and $1 \mathrm{mM}$, respectively, compared with RPMI alone (Fig. 2A). KN was as effective as tryptophane but not as potent as DMEM in driving goblet cell differentiation. Next, we tested whether inhibition of KN synthesis suppresses goblet cell differentiation. To do this, HT-29 cells were grown in DMEM supplemented with 1-MT. Muc2 expression gradually decreased in DMEM supplemented with 1-MT as the concentration of $1-\mathrm{MT}$ increased $(\mathrm{P}=0.017$ for $0.1 \mathrm{mM}$; $\mathrm{P}=0.002$ for $1 \mathrm{mM}$ ) (Fig. 2B). Thus, it appears that $\mathrm{KN}$ is involved in the goblet cell differentiation of HT-29 cells.

AhR activation promotes the differentiation of goblet cells from HT-29 cells. As described earlier in the 'Introduction' section, $\mathrm{KN}$ is a ligand of $\mathrm{AhR}$. KN activates $\mathrm{AhR}$ in various tumors (23). Thus, it is possible that KN promotes goblet cell differentiation via activating AhR. To test this, we first exam- 


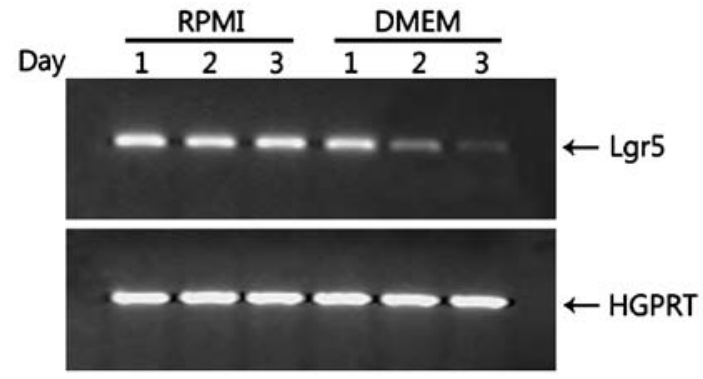

Figure 3. Lgr5 expression is decreased in HT-29 cells grown in DMEM. HT-29 cells in RPMI or DMEM were cultured for 1-3 days and harvested for RNA analysis by RT-PCR. Results are representative of 3 separate experiments which showed similar results.

ined whether HT-29 cells express and activate AhR. HT-29 cells grown in both RPMI and DMEM constitutively expressed AhR (Fig. 2C). Next, we tested whether AhR is functional in HT-29 cells by examining AhR ligand-induced expression of Cyp1A1, a target gene of AhR. Expression of Cyp1A1 was induced in HT-29 cells cultured in both RPMI and DMEM by the addition of FICZ (Fig. 2C). HT-29 cells were cultured in RPMI in the presence of various AhR ligands, including FICZ, I3S, DIM and I3C (24). Muc2 expression was increased by all the AhR ligands tested with FICZ being the most effective $(\mathrm{P}=0.000025$ for FICZ; $\mathrm{P}=0.0002$ for $\mathrm{I} 3 \mathrm{~S} ; \mathrm{P}=0.008$ for DIM; $\mathrm{P}=0.003$ for $\mathrm{I3C}$ ) (Fig. 2D), although AhR activation itself was not as effective as DMEM in promoting Muc2 expression (Fig. 1B). In addition, Muc2 expression in HT-29 cells grown in DMEM was reduced by $\alpha$-naphthoflavone $(\mathrm{P}=0.008)$, an AhR antagonist, compared with $\mathrm{PBS}$ or vector control (0.1\% DMSO), suggesting that DMSO-induced goblet cell differentiation is partly mediated by AhR (Fig. 2E).

Lgr5 expression is greatly reduced in HT-29 cells grown in DMEM. Lgr5, a marker for intestinal stem cells, is also required for the maintenance and proliferation of colorectal cancer cells via the Wnt $3 / \beta$-catenin signaling pathway $(25,26)$. HT-29 cells grown in RPMI expressed Lgr5 (Fig. 3). Thus, we examined whether Lgr5 expression is modulated by changes in the medium. Once HT-29 cells were cultured with DMEM, they started to show reduced expression of Lgr5, barely expressing Lgr5 at day 3 (Fig. 3), suggesting that Lgr5 is required for proliferation of HT-29 cells so that the reduced expression of Lgr5 may allow HT-29 cells to differentiate into Lgr5-intestinal lineages such as goblet cells.

Wht and Notch signaling pathways are modulated in HT-29 cells grown in DMEM. The $\mathrm{Wnt} 3 / \beta$-catenin signaling pathway, which is necessary for the proliferation of colorectal cancer cells as described earlier, also plays a key role in the proliferation of intestinal stem cells $(27,28)$. Notch is also involved in the proliferation and differentiation of intestinal stem cells. In the intestine, Notch has dual functions in the crypt: it directs proliferation of $\mathrm{Lgr}^{+}$stem cells in concert with Wnt (29) and induces enterocyte differentiation when Wnt signals are low (30). Inhibition of the Notch pathway results in a massive increase in goblet cells whereas its activation results in goblet cell depletion (30). Thus, we examined whether the Wnt and Notch pathways are modulated by medium changes. Canonical Wnt signaling leads to stabilization of cytoplasmic $\beta$-catenin through the inhibition of phosphorylation events that otherwise target the protein for proteosomal degradation (31). In mice, the Wnt signals exhibit a spatial gradient along the crypt-villus axis, with the highest activity in proliferating crypt and the lowest activity in differentiating villus where goblet cells reside (32). To ascertain the effects of DMEM on Wnt activity, we measured the level of non-phosphorylated (active) (Ser33/37/Thr41) $\beta$-catenin at earlier time points when goblet cell differentiation was not yet completed. At day 2 , there was no difference between the levels of active $\beta$-catenin in HT-29 cells grown in RPMI and DMEM (Fig. 4A). The levels of active $\beta$-catenin were increased $\sim 2$-fold irrespective of media when 1-MT was added to the culture while being decreased $\sim 2$-fold by the addition of KN (Fig. 4A). These results suggest that the Wnt signal, which is active in HT-29 cells, is regulated by tryptophan metabolism.

In mouse intestine, Notch1 and Notch2 are specifically expressed in crypt stem cells (33). The Notch pathway is activated by a cascade of proteolytic cleavages, resulting in
A

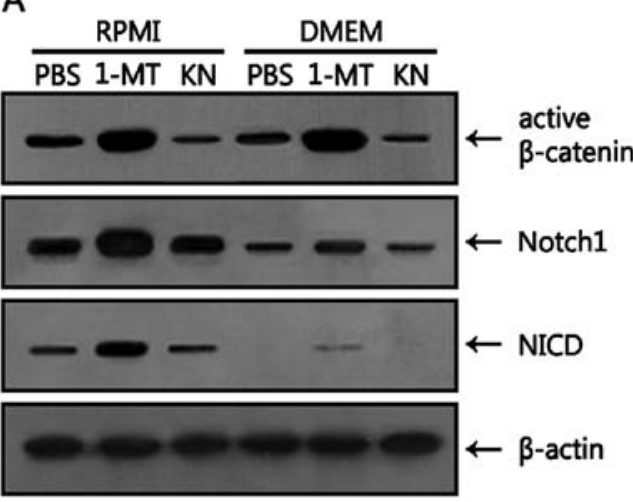

B

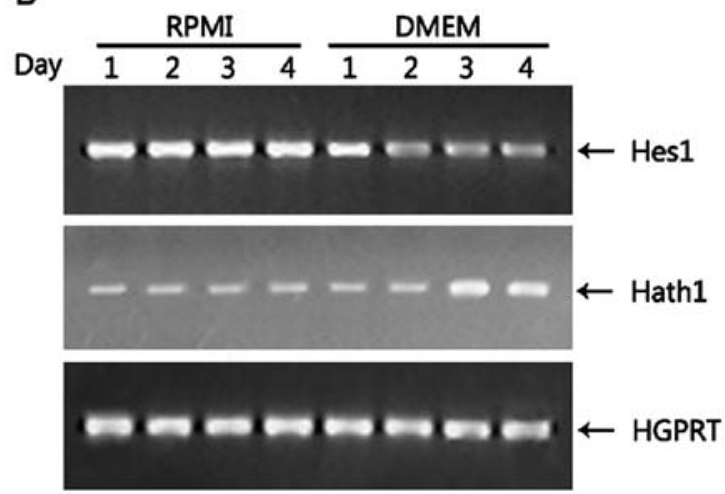

Figure 4. Wnt and Notch signals are modulated by DMEM and tryptophan metabolism. (A) For $\beta$-catenin and Notch1 analysis, HT-29 cells were grown for 2 days in RPMI or DMEM supplemented with KN (1 mM) and 1-MT (1 mM) and harvested for protein analysis by western blotting. For NICD analysis, HT-29 cells were grown for 2 days in RPMI or DMEM supplemented with KN (1 mM) and 1-MT (1 mM), treated with Jagged-1 peptide ( $1 \mu \mathrm{M})$ for $2 \mathrm{~h}$ and harvested for protein analysis by western blotting. (B) For Hes1 and Hath1 expression, HT-29 cells were grown up to 4 days in RPMI or DMEM and harvested for RNA analysis by RT-PCR. Results are representative of 3 separate experiments which showed similar results. 
the translocation of NICD into the nucleus to induce target gene transcription via interactions with other DNA binding proteins (34). We first examined the levels of unprocessed Notch1 protein at day 2. The level of Notch1 was markedly reduced ( 2.5-fold) in HT-29 cells grown in DMEM compared with RPMI (Fig. 4A). The level of Notch1 was increased by the addition of 1-MT in both culture media, although the effects of 1-MT were more pronounced in RPMI than in DMEM. However, addition of KN to both culture media did not change the level of Notch1. Then, the level of NICD was measured $2 \mathrm{~h}$ after the addition of Jagged-1 peptide. NICD, which was detectable in HT-29 cells grown in RPMI, was not detected when cells were cultured in DMEM (Fig. 4A). When 1-MT was added to the culture media, the level of NICD was increased compared with PBS control in both culture media, although the level of NICD in HT-29 cells grown in RPMI was significantly higher than in DMEM. KN showed little effect on the amount of NICD in HT-29 cells grown in both media treated with Jagged-1 peptide. Hes1, which is a known Notch target gene (35), is a transcriptional repressor which represses transcription of the transcription factor Math1 (Hath1 in humans) (36). Intestinal Math1 expression is required for commitment toward the secretory lineage, including goblet and Paneth cells (37). Thus, we performed kinetic analyses of the expression of Hes1 and Hath1 in HT-29 cells. The level of Hes1, which remained constant in HT-29 cells grown in RPMI, was reduced 1 day after culturing in DMEM, remaining unchanged thereafter (Fig. 4B). In contrast, the level of Hath1, which was constant in HT-29 cells cultured in RPMI, was increased 2 days after culture in DMEM. These results suggest that reduced activation of Notch1 resulting from the decreased expression of Notch1 in HT-29 cells grown in DMEM promotes the differentiation of goblet cells.

\section{Discussion}

Although the Notch pathway plays an important role in determining lineage decisions between absorptive enterocyte and secretory cell differentiation $(29,30)$, there are subtle differences in signaling required for the differentiation of Paneth, goblet and enteroendocrine cells: Paneth cells require a high Wnt signal along with Lgr4 while differentiation of goblet and enteroendocrine cell needs low and no Wnt activity, respectively $(29,38,39)$. In the present study, we demonstrated that DMEM induced goblet cell differentiation from HT-29 colon cancer stem cells in a lineage-specific manner. Tryptophan metabolism partially mediated the activity of DMEM via regulating Wnt, Notch and AhR signals.

Tryptophan, which is richer in DMEM than in RPMI, functions as the precursor to many substances, including $\mathrm{KN}, \mathrm{KA}$ and melatonin (21). KN, the first breakdown product of tryptophan mediated by indoleamine-2,3dioxygenases 1 and 2 (IDO1/2) or tryptophan-2,3-dioxygenase (TDO), activates the aryl hydrocarbon receptor (AhR), a ligand-activated transcription factor, in various tumors (16). KN shows contrasting effects on cell growth depending on cell type; it inhibits growth of lymphoid cell lines (40) while promoting proliferation of non-lymphoid tumor cell lines (22). In the present study, we observed that $\mathrm{KN}$ reduced $\beta$-catenin expression, which was increased by IDO-1 inhibitor 1-MT. How
$\mathrm{KN}$ regulates $\beta$-catenin expression is not known. However, as a ligand-activated transcriptional factor, $\mathrm{AhR}$ has a role as a ligand-dependent E3 ubiquitin ligase of certain nuclear receptors such as the androgen and estrogen receptors (41). It was recently shown that the AhR E3 ubiquitin ligase activated by natural ligands, such as indole derivatives that are converted from dietary tryptophan by intestinal microbes, degraded $\beta$-catenin, suppressing intestinal carcinogenesis (42). As presented earlier in the present study, AhR functions in HT-29 cells (Fig. 2C). Thus, it is possible that $\beta$-catenin degradation is mediated by activation of AhR by KN. Alternatively, KN may reduce $\beta$-catenin expression via its metabolites. KA, a metabolite of the KN pathway of tryptophan degradation, is synthesized in colon-derived normal and cancer cells (43). KA inhibited proliferation of several cancer cell lines including colon cancer cell lines by inhibiting the activation of Akt, ERK1/2 and p38 kinase (43). KA also works as an AhR ligand (17). Whether KA mediates goblet cell differentiation remains to be elucidated.

In the present study, Notch1 expression was reduced in HT-29 cells grown in DMEM compared with RPMI. In addition, 1-MT increased Notch 1 expression in both media. How DMEM or IDO-1 activity reduces Notch1 expression is not known. AhR promotes expression of Notch receptors and Notch1 in the testes and NKp46 cells, respectively $(44,45)$, making it unlikely that transcriptional regulation of Notch1 is mediated by $\mathrm{KN}$. As for $\beta$-catenin degradation by $\mathrm{AhR}$, Notch1 could be degraded by AhR activation, which remains to be tested. Alternatively, melatonin could be involved in this event. In the intestine, tryptophan is metabolized to $\mathrm{KN}$ and melatonin (46-48). Melatonin, which is synthesized from tryptophan by enzymes $N$-acetyltransferase and acetylserotonin methyltransferase, is produced in many tissues, including the gastrointestinal tract as well as in the pineal gland $(47,48)$. Melatonin has been shown to inhibit proliferation of many types of cancer cells such as glioblastoma cells, colon cancer cells, and breast cancer cells (49-51). Melatonin exerts its anti-proliferative activity by inactivating FoxO-1 and $\mathrm{NF}-\kappa \mathrm{B}$ transcription factors, downregulating myosin light chain kinase expression through cross-talk with p38 MAPK, or by suppressing Notch1 signaling $(49,52,53)$. It remains to be tested whether melatonin is involved in goblet cell differentiation by regulating Notch1 expression.

Notch and Wnt signals interact to regulate target gene expression $(54,55)$. NICD binds directly to $\beta$-catenin and translocates to the nucleus, where it forms a transcriptional activator complex with the protein CSL to transcribe target genes such as Hes1. In the present study, it was observed that Hes1 expression was reduced whereas Hath1 expression was increased in HT-29 cells grown in DMEM. Notch and Wnt $\beta$-catenin signaling can interact to induce expression of Hes1 by forming a transcriptional complex of NICD and $\beta$-catenin (54). Thus, it is possible that reduced formation of the transcriptional complex of NICD and $\beta$-catenin in DMEM downregulates the expression of Hes1 which represses Hath1 expression, resulting in the promotion of goblet cell differentiation.

In the present study, Lgr5 expression gradually decreased, being almost not detected at day 4 when most of HT-29 cells appeared to be differentiated into goblet cells. Leucine-rich- 
repeat-containing G-protein-coupled receptor 5 (Lgr5), which is a receptor for R-spondins and participates in canonical Wnt signaling (56), is expressed in crypt base columnar cells and functions as a stem cell marker (57). Lgr5 expression is upregulated by Wnt activity (57). In addition, Wnt/ $\beta$-catenin signaling which plays important roles in the generation of $\mathrm{Lgr}^{+}$stem cells is regulated by nonreceptor tyrosine phosphatase Shp2mediated MAPK signaling $(20,58)$. How Lgr5 expression in colon cancer stem cells is regulated by tryptophan metabolism remains to be illustrated.

$\mathrm{AhR}$ is a ligand-activated transcription factor that belongs to the basic region-helix-loop-helix (bHLH) superfamily of DNA binding proteins (59). However, environmental toxicants, such as 2,3,7,8-tetrachlorodibenzo- $p$-dioxin (TCDD), a number of structurally diverse low-molecular-weight chemicals, including indoles and tryptophan metabolites, have been identified as naturally occurring exogenous and endogenous AhR ligands (60). AhR regulates proliferation and differentiation of various stem cells. Hematopoietic stem cells (HSCs) from AhR-knockout mice were hyper-proliferative and had an altered cell cycle (61). TCDD and FICZ inhibited proliferation of stem cells derived from the apical papilla (SCAPs) and HL-60 myeloblastic leukemia cells, respectively, while increasing proliferation of rodent hepatic stem cells (62-64). It was previously reported that FICZ and TCDD inhibit the development of intestinal organoids from crypts or $\mathrm{Lgr}^{+}$stem cells in vitro (65). In the present study, AhR activation partially induced goblet cell differentiation. How AhR induces goblet cell differentiation is unknown. It may directly or indirectly transcriptionally regulate the expression of Notch1, Hes1 or Hath1. Alternatively, it works by interacting with Notch and Wnt signals as described earlier.

Although tryptophan and $\mathrm{KN}$ induced goblet cell differentiation, they were not as effective as DMEM, which suggests that factors other than tryptophan metabolites could contribute to goblet cell differentiation. FICZ, which can be produced from tryptophan in light-exposed media, could be partially responsible for goblet cell differentiation (1). Other amino acids may contribute to goblet cell differentiation. Self-renewal and differentiation of mouse embryonic stem cells are critically dependent on the metabolism of proline, threonine and methionine, which works as signal molecules (proline) or precursors for donor molecules used in histone methylation and acetylation (threonine and methionine) (66). Histidine, tyrosine and phenylalanine could generate precursors for AhR ligands (18).

In conclusion, the results obtained in the present study provide evidence that tryptophan metabolites induce the goblet cell differentiation of colon cancer stem cells by regulating the Wnt, Notch and AhR signaling pathways. The present findings may provide clues to understanding goblet cell differentiation from intestinal crypts. The following questions remain to be answered. i) Are amino acids other than tryptophan also involved in goblet cell differentiation? ii) How is Notch1 expression regulated? iii) Does DMEM also regulate the differentiation of other stem cells?

\section{Acknowledgements}

Not applicable.

\section{Funding}

The present study was supported by Changwon National University grants (2017-2018).

\section{Availability of data and materials}

The data used and/or analyzed during the present study are available from the corresponding author on reasonable request.

\section{Authors' contributions}

JHP designed research; JML, EJL, DJK and WBH performed research and JHP, JML, EJL, DJK and WBH analyzed and interpreted data. JML, EJL, DJK and WBH were involved in drafting the manuscript and JHP revised it. All authors approved the final version to be published and agreed to be accountable for all aspects of the work in ensuring that questions related to the accuracy or integrity of any part of the work are appropriately investigated and resolved.

\section{Ethics approval and consent to participate}

Not applicable.

\section{Consent for publication}

Not applicable.

\section{Competing interests}

The authors declare that they have no competing interests.

\section{References}

1. Veldhoen M, Hirota K, Christensen J, O'Garra A and Stockinger B: Natural agonists for aryl hydrocarbon receptor in culture medium are essential for optimal differentiation of Th17 T cells. J Exp Med 206: 43-49, 2009.

2. Ilchmann A, Krause M, Heilmann M, Burgdorf S, Vieths S and Toda M: Impact of culture medium on maturation of bone marrow-derived murine dendritic cells via the aryl hydrocarbon receptor. Mol Immunol 51: 42-50, 2012.

3. Wu KL, Chang SH, Manousakas I, Huang HH, Teong B, Chuang CW and Kuo SM: Effects of culturing media on hepatocytes differentiation using Volvox sphere as co-culturing vehicle. Biochem Biophys Res Commun 458: 620-625, 2015.

4. Sidney LE, Branch MJ, Dua HS and Hopkinson A: Effect of culture medium on propagation and phenotype of corneal stroma-derived stem cells. Cytotherapy 17: 1706-1722, 2015.

5. Kim SW, Kim SJ, Langley RR and Fidler IJ: Modulation of the cancer cell transcriptome by culture media formulations and cell density. Int J Oncol 46: 2067-2075, 2015.

6. Zweibaum A, Pinto M, Chevalier G, Dussaulx E, Triadou N, Lacroix B, Haffen K, Brun JL and Rousset M: Enterocytic differentiation of a subpopulation of the human colon tumor cell line HT-29 selected for growth in sugar-free medium and its inhibition by glucose. J Cell Physiol 122: 21-29, 1985.

7. Chastre E, Emami S, Rosselin G and Gespach C: Vasoactive intestinal peptide receptor activity and specificity during enterocyte-like differentiation and retrodifferentiation of the human colonic cancerous subclone HT29-18. FEBS Lett 188: 197-204, 1985

8. Velcich A, Palumbo L, Jarry A, Laboisse C, Racevskis J and Augenlicht L: Patterns of expression of lineage-specific markers during the in vitro-induced differentiation of HT29 colon carcinoma cells. Cell Growth Differ 6: 749-757, 1995. 
9. Huet C, Sahuquillo-Merino C, Coudrier E and Louvard D: Absorptive and mucus-secreting subclones isolated from a multipotent intestinal cell line (HT-29) provide new models for cell polarity and terminal differentiation. J Cell Biol 105: 345-357, 1987.

10. Boultwood J, Yip BH, Vuppusetty C, Pellagatti A and Wainscoat JS: Activation of the mTOR pathway by the amino acid ${ }_{\mathrm{L}}$-leucine in the 5q- syndrome and other ribosomopathies. Adv Biol Regul 53: 8-17, 2013.

11. Ma X, Han M, Li D, Hu S, Gilbreath KR, Bazer FW and Wu G: $\mathrm{L}$-Arginine promotes protein synthesis and cell growth in brown adipocyte precursor cells via the mTOR signal pathway. Amino Acids 49: 957-964, 2017.

12. Zhai Y, Sun Z, Zhang J, Kang K, Chen J and Zhang W: Activation of the TOR signalling pathway by glutamine regulates insect fecundity. Sci Rep 5: 10694, 2015.

13. Swamy M, Pathak S, Grzes KM, Damerow S, Sinclair LV, van Aalten DM and Cantrell DA: Glucose and glutamine fue protein $\mathrm{O}-\mathrm{GlcN} A c y l a t i o n$ to control $\mathrm{T}$ cell self-renewal and malignancy. Nat Immunol 17: 712-720, 2016.

14. Chen $\mathrm{G}$ and Wang J: Threonine metabolism and embryonic stem cell self-renewal. Curr Opin Clin Nutr Metab Care 17: 80-85, 2014

15. Green CR, Wallace M, Divakaruni AS, Phillips SA, Murphy AN Ciaraldi TP and Metallo CM: Branched-chain amino acid catabolism fuels adipocyte differentiation and lipogenesis. Nat Chem Biol 12: 15-21, 2016.

16. Rannug U, Rannug A, Sjöberg U, Li H, Westerholm R and Bergman J: Structure elucidation of two tryptophan-derived, high affinity Ah receptor ligands. Chem Biol 2: 841-845, 1995.

17. DiNatale BC, Murray IA, Schroeder JC, Flaveny CA, Lahoti TS, Laurenzana EM, Omiecinski CJ and Perdew GH: Kynurenic acid is a potent endogenous aryl hydrocarbon receptor ligand that synergistically induces interleukin- 6 in the presence of inflammatory signaling. Toxicol Sci 115: 89-97, 2010.

18. Paine AJ and Francis JE: The induction of benzo[a]pyrene-3mono-oxygenase by singlet oxygen in liver cell culture is mediated by oxidation products of histidine. Chem Biol Interact 30: 343-353, 1980.

19. Choi HJ, Kim J, Park SH, Do KH, Yang H and Moon Y: Pro-inflammatory NF- $\kappa \mathrm{B}$ and early growth response gene 1 regulate epithelial barrier disruption by food additive carrageenan in human intestinal epithelial cells. Toxicol Lett 211: $289-295,2012$

20. Heuberger J, Kosel F, Qi J, Grossmann KS, Rajewsky K and Birchmeier W: Shp2/MAPK signaling controls goblet/paneth cell fate decisions in the intestine. Proc Natl Acad Sci USA 111: 3472-3477, 2014

21. Badawy AA: Tryptophan metabolism in alcoholism. Nutr Res Rev 15: 123-152, 2002.

22. Thaker AI, Rao MS, Bishnupuri KS, Kerr TA, Foster L, Marinshaw JM, Newberry RD, Stenson WF and Ciorba MA: IDO1 metabolites activate $\beta$-catenin signaling to promote cancer cell proliferation and colon tumorigenesis in mice. Gastroenterology 145: 416-25.e1, 4, 2013.

23. Opitz CA, Litzenburger UM, Sahm F, Ott M, Tritschler I, Trump S, Schumacher T, Jestaedt L, Schrenk D, Weller M, et al An endogenous tumour-promoting ligand of the human aryl hydrocarbon receptor. Nature 478: 197-203, 2011.

24. Nguyen LP and Bradfield CA: The search for endogenous activators of the aryl hydrocarbon receptor. Chem Res Toxicol 21: 102-116, 2008

25. Chen X, Wei B, Han X, Zheng Z, Huang J, Liu J, Huang Y and Wei H: LGR 5 is required for the maintenance of spheroidderived colon cancer stem cells. Int J Mol Med 34: 35-42, 2014.

26. Lin YU, Wu T, Yao Q, Zi S, Cui L, Yang M and Li J: LGR5 promotes the proliferation of colorectal cancer cells via the Wnt/ $\beta$-catenin signaling pathway. Oncol Lett 9: 2859-2863, 2015.

27. Reya $\mathrm{T}$ and Clevers $\mathrm{H}$ : Wnt signalling in stem cells and cancer. Nature 434: 843-850, 2005

28. Pećina-Slaus N: Wnt signal transduction pathway and apoptosis: A review. Cancer Cell Int 10: 22, 2010.

29. Fre S, Huyghe M, Mourikis P, Robine S, Louvard D and Artavanis-Tsakonas S: Notch signals control the fate of immature progenitor cells in the intestine. Nature 435: 964-968, 2005.

30. van Es JH, van Gijn ME, Riccio O, van den Born M, Vooijs M, Begthel H, Cozijnsen M, Robine S, Winton DJ, Radtke F, et al: Notch/gamma-secretase inhibition turns proliferative cells in intestinal crypts and adenomas into goblet cells. Nature 435 959-963, 2005

31. MacDonald BT, Tamai K and He X: Wnt/beta-catenin signaling: Components, mechanisms, and diseases. Dev Cell 17: 9-26, 2009.
32. Vries RG, Huch M and Clevers H: Stem cells and cancer of the stomach and intestine. Mol Oncol 4: 373-384, 2010.

33. Fre S, Hannezo E, Sale S, Huyghe M, Lafkas D, Kissel H, Louvi A, Greve J, Louvard D and Artavanis-Tsakonas S: Notch lineages and activity in intestinal stem cells determined by a new set of knock-in mice. PLoS One 6: e25785, 2011.

34. Bray SJ: Notch signalling: A simple pathway becomes complex. Nat Rev Mol Cell Biol 7: 678-689, 2006.

35. Ohtsuka T, Ishibashi M, Gradwohl G, Nakanishi S, Guillemot F and Kageyama R: Hesl and Hes 5 as Notch effectors in mammalian neuronal differentiation. EMBO J 18: 2196-2207, 1999.

36. Jensen J, Pedersen EE, Galante P, Hald J, Heller RS, Ishibashi M, Kageyama R, Guillemot F, Serup P and Madsen OD: Control of endodermal endocrine development by Hes-1. Nat Genet 24: 36-44, 2000

37. Yang Q, Bermingham NA, Finegold MJ and Zoghbi HY: Requirement of Math1 for secretory cell lineage commitment in the mouse intestine. Science 294: 2155-2158, 2001.

38. Sansom OJ, Reed KR, Hayes AJ, Ireland H, Brinkmann H, Newton IP, Batlle E, Simon-Assmann P, Clevers H, Nathke IS, et al: Loss of Apc in vivo immediately perturbs Wnt signaling, differentiation, and migration. Genes Dev 18: 1385-1390, 2004.

39. Wang Y, Giel-Moloney M, Rindi G and Leiter AB: Enteroendocrine precursors differentiate independently of Wnt and form serotonin expressing adenomas in response to active betacatenin. Proc Natl Acad Sci USA 104: 11328-11333, 2007.

40. Suwa S, Kasubata A, Kato M, Iida M, Watanabe K, Miura O and Fukuda T: The tryptophan derivative, tranilast, and conditioned medium with indoleamine 2,3-dioxygenase-expressing cells inhibit the proliferation of lymphoid malignancies. Int $\mathrm{J}$ Oncol 46: 1369-1376, 2015.

41. Ohtake F, Baba A, Takada I, Okada M, Iwasaki K, Miki H, Takahashi S, Kouzmenko A, Nohara K, Chiba T, et al: Dioxin receptor is a ligand-dependent E3 ubiquitin ligase. Nature 446: 562-566, 2007.

42. Kawajiri K, Kobayashi Y, Ohtake F, Ikuta T, Matsushima Y, Mimura J, Pettersson S, Pollenz RS, Sakaki T, Hirokawa T, et al: Aryl hydrocarbon receptor suppresses intestinal carcinogenesis in $\mathrm{Apc}^{\mathrm{Min} / \mathrm{+}}$ mice with natural ligands. Proc Natl Acad Sci USA 106: 13481-13486, 2009.

43. Walczak K, Dabrowski W, Langner E, Zgrajka W, Piłat J, Kocki T, Rzeski W and Turski WA: Kynurenic acid synthesis and kynurenine aminotransferases expression in colon derived normal and cancer cells. Scand J Gastroenterol 46: 903-912, 2011.

44. Huang B, Butler R, Miao Y, Dai Y, Wu W, Su W, Fujii-Kuriyama Y, Warner M and Gustafsson JA: Dysregulation of Notch and ERa signaling in $\mathrm{AhR}^{-/-}$male mice. Proc Natl Acad Sci USA 113: 11883-11888, 2016

45. Lee JS, Cella M, McDonald KG, Garlanda C, Kennedy GD, Nukaya M, Mantovani A, Kopan R, Bradfield CA, Newberry RD, et al: AHR drives the development of gut ILC22 cells and postnatal lymphoid tissues via pathways dependent on and independent of Notch. Nat Immunol 13: 144-151, 2011.

46. Badawy AA: Kynurenine pathway of tryptophan metabolism: Regulatory and functional aspects. Int J Tryptophan Res 10: $1178646917691938,2017$.

47. Poon AM, Mak AS and Luk HT: Melatonin and 2[125I]iodomelatonin binding sites in the human colon. Endocr Res 22: 77-94, 1996.

48. Vician M, Zeman M, Herichová I, Juráni M, Blazícek P and Matis P: Melatonin content in plasma and large intestine of patients with colorectal carcinoma before and after surgery. J Pineal Res 27: 164-169, 1999.

49. Zheng X, Pang B, Gu G, Gao T, Zhang R, Pang Q and Liu Q: Melatonin inhibits glioblastoma stem-like cells through suppression of EZH2-NOTCH1 signaling axis. Int J Biol Sci 13: 245-253, 2017.

50. García-Navarro A, González-Puga C, Escames G, López LC, López A, López-Cantarero M, Camacho E, Espinosa A, Gallo MA and Acuña-Castroviejo D: Cellular mechanisms involved in the melatonin inhibition of HT-29 human colon cancer cell proliferation in culture. J Pineal Res 43: 195-205, 2007.

51. Zha L, Fan L, Sun G, Wang H, Ma T, Zhong F and Wei W: Melatonin sensitizes human hepatoma cells to endoplasmic reticulum stress-induced apoptosis. J Pineal Res 52: 322-331, 2012

52. León J, Casado J, Jiménez Ruiz SM, Zurita MS, González-Puga C, Rejón JD, Gila A, Muñoz de Rueda P, Pavón EJ, Reiter RJ, et al: Melatonin reduces endothelin-1 expression and secretion in colon cancer cells through the inactivation of FoxO-1 and NF- $\kappa \beta$. J Pineal Res 56: 415-426, 2014 
53. Zou DB, Wei X, Hu RL, Yang XP, Zuo L, Zhang SM, Zhu HQ Zhou Q, Gui SY and Wang Y: Melatonin inhibits the migration of colon cancer RKO cells by down-regulating myosin light chain kinase expression through cross-talk with p38 MAPK. Asian Pac J Cancer Prev 16: 5835-5842, 2015.

54. Yamamizu K, Matsunaga T, Uosaki H,Fukushima H, Katayama S, Hiraoka-Kanie M, Mitani K and Yamashita JK: Convergence of Notch and beta-catenin signaling induces arterial fate in vascular progenitors. J Cell Biol 189: 325-338, 2010.

55. Collu GM, Hidalgo-Sastre A, Acar A, Bayston L, Gildea C, Leverentz MK, Mills CG, Owens TW, Meurette O, Dorey K, et al: Dishevelled limits Notch signalling through inhibition of CSL. Development 139: 4405-4415, 2012.

56. Sato T, van Es JH, Snippert HJ, Stange DE, Vries RG van den Born M, Barker N, Shroyer NF, van de Wetering M and Clevers H: Paneth cells constitute the niche for Lgr5 stem cells in intestinal crypts. Nature 469: 415-418, 2011.

57. Barker N, van Es JH, Kuipers J, Kujala P, van den Born M, Cozijnsen M, Haegebarth A, Korving J, Begthel H, Peters PJ, et al: Identification of stem cells in small intestine and colon by marker gene Lgr5. Nature 449: 1003-1007, 2007.

58. Schuijers J and Clevers H: Adult mammalian stem cells: The role of Wnt, Lgr5 and R-spondins. EMBO J 31: 2685-2696, 2012.

59. Burbach KM, Poland A and Bradfield CA: Cloning of the Ah-receptor cDNA reveals a distinctive ligand-activated transcription factor. Proc Natl Acad Sci USA 89: 8185-8189, 1992.
60. Denison MS and Nagy SR: Activation of the aryl hydrocarbon receptor by structurally diverse exogenous and endogenous chemicals. Annu Rev Pharmacol Toxicol 43: 309-334, 2003.

61. Gasiewicz TA, Singh KP and Bennett JA: The Ah receptor in stem cell cycling, regulation, and quiescence. Ann NY Acad Sci 1310: 44-50, 2014

62. Bunaciu RP and Yen A: 6-Formylindolo (3,2-b)carbazole (FICZ) enhances retinoic acid (RA)-induced differentiation of HL-60 myeloblastic leukemia cells. Mol Cancer 12: 39, 2013.

63. Guo H, Zhang L, Wei K, Zhao J, Wang Y, Jin F and Xuan K: Exposure to a continuous low dose of tetrachlorodibenzo-pdioxin impairs the development of the tooth root in lactational rats and alters the function of apical papilla-derived stem cells. Arch Oral Biol 60: 199-207, 2015.

64. Harrill JA, Parks BB, Wauthier E, Rowlands JC, Reid LM and Thomas RS: Lineage-dependent effects of aryl hydrocarbon receptor agonists contribute to liver tumorigenesis. Hepatology 61: 548-560, 2015.

65. Park JH, Choi AJ, Kim SJ, Cheong SW and Jeong SY: AhR activation by 6 -formylindolo[3,2- $b]$ carbazole and $2,3,7,8$-tetrachlorodibenzo- $p$-dioxin inhibit the development of mouse intestinal epithelial cells. Environ Toxicol Pharmacol 43: 44-53, 2016.

66. Kilberg MS, Terada N and Shan J: Influence of amino acid metabolism on embryonic stem cell function and differentiation. Adv Nutr 7: 780S-789S, 2016. 